\title{
The quest for temperature and hydroclimate records
}

Anne Hormes ${ }^{1}$ and Jostein Bakke ${ }^{2}$

The Arctic is characterized by a high diversity of paleoclimate archives, resulting in reconstructions that integrate multiple proxy evidence. At a workshop in San Francisco, USA, on 8 December 2013, Arctic2k took stock of its status and discussed scientific objectives and organizational structures for the coming phase of the project.

\section{Phase I: Mission completed}

In 2013, Arctic2k reached a milestone by contributing a data collection and 2000-year long temperature reconstruction to the benchmark paper by the PAGES2k Consortium (2013). Since then, the Arctic $2 k$ temperature reconstruction has been revised based on updates and corrections to the dataset. The revisions result in more pronounced decadal-scale variability and in amplification of the pre- $20^{\text {th }}$ century cooling trend (McKay and Kaufman 2014). The dataset now also includes the geochronologic data for the sedimentary records and age models based on a uniform approach for all records.

Here we would like to thank Atte Korhola and Sami Hanhijärvi (Helsinki, Finland) for their leadership, data management and analysis during Phase I, as well Nalân Koç (Tromsø, Norway) for initiating Arctic2k back in 2008.

\section{Phase II: Hydroclimate and temperature} Jostein Bakke and Anne Hormes, the co-authors of this article, were designated as the new co-leaders of Arctic2k. They are supported by the data managers and proxy-specific coordinators helping with the inclusion of new records. For activities beyond the data collection, points of contact were established for specific methods and regions (see Arctic $2 k$ website).

The goal for Phase II is to produce multi-proxy based spatial reconstructions for temperature, precipitation and humidity for comparison with the model output of PMIP3 simulations. The first step towards this goal is to expand the Arctic proxy data collection with precipitation and humidity records.

The following goals and timeline were defined:

- Arctic2k meeting in April 2015 at EGU in Vienna

- Final version of the T and P database by 2015

- Regional temperature field reconstructions in 2015

- Comparison of spatial sea ice and climate reconstructions in 2015

- Hydroclimate reconstructions in 2015-2016

- Atmospheric pressure field reconstructions in 2015-2016

- Forcing vs climate signal analysis in 2015-2016

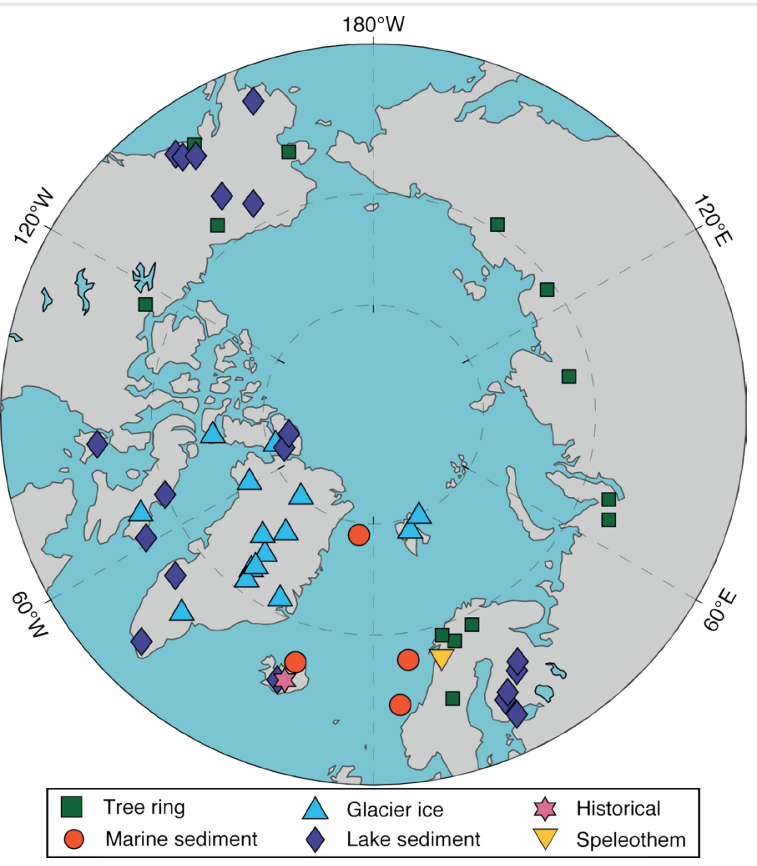

Figure 1: Map of the Arctic showing the location and type of temperature proxy records in the PAGES Arctic2k database. Modified from McKay and Kaufman (2014).

Three papers focusing on the following topics are in preparation:

1. Temperature field reconstruction using annually resolved records in the North-Atlantic region (J. Werner, M. Debret, H. Linderholm et al.).

2. Methods for hydro-climate reconstruction in the Arctic (A. Hormes, J. Bakke, W. d'Andrea, F. Lundqvist, J. Werner, H. Linderholm et al.). 3. Integration of marine and terrestrial paleoclimate records from the Svalbard-Barents Sea (E. Isaksson, D. Divine, K. Husum, J. Werner, M. Debret, A. Hormes, A. Miettinen et al.).

Please let us know if you would like to contribute to these publications or if you are planning additional papers using the Arctic2k database.

\section{Arctic2k needs your input!}

Temperature records currently in the Arctic $2 k$ database are shown in Figure 1. Some regions, such as the Russian or Canadian Arctic still yield few temperature records, while precipitation and humidity records still need to be collected for all regions. The task for the community of Arctic paleo-researchers over the coming months is therefore to complete the database with temperature or hydroclimate records fulfilling the following criteria:

- Demonstrated plausible mechanistic relation to climate

- At least one numerical age per 500-year interval

- At least one analysis every 200 years
- Must span at least 500 years during the past $2 \mathrm{k}$

- Must be published in a peer-reviewed journal

- Must be made available once used for a PAGES2k publication

If you are aware of records that fulfill these criteria, please contact the Artic2k data managers Dmitri Divine or Johannes Werner. All new data will first be used internally by the PAGES $2 \mathrm{k}$ Network and be archived publicly once a product is published.

Finally, if you would like to participate in Arctic2k and contribute to our scientific objec tives and publications, please contact us. You can also subscribe to the Arctic $2 \mathrm{k}$ mailing list. Visit www.pages-igbp.org/workinggroups/ arctic $2 k$ for more information. The updated Arctic2k database is available here: www.ncdc. noaa.gov/paleo/pages2k/pages-arctic-2k.html

\section{AFFILIATIONS}

'Department of Earth Sciences, University of Gothenburg, Sweden

${ }^{2}$ Department of Earth Science and Bjerknes Centre for Climate Research, University of Bergen, Norway

\section{CONTACT}

Anne Hormes: anne.hormes@gvc.gu.se

\section{REFERENCES}

Hanhijärvi S et al. (2013) Clim Dyn 41: 2039-2060 Kaufman DS et al. (2013) Global Change 81: 17-23 McKay N, Kaufman D (2014) Sci Data 1, doi:10.1038/ sdata.2014.26

PAGES 2k Consortium (2013) Nat Geosci 6: 339-346 